\title{
A Comparison of Privileged Access Interviewing and Traditional Interviewing Methods when Studying Drug Users in Treatment
}

\begin{abstract}
Aims: Privileged Access Interviewing (PAI) has traditionally been used to reach illicit drug users and other 'hidden' populations. How PAI data compare to other self-reported data has seldom been discussed. We compare data from patients in opioid substitution treatment (OST), gathered through PAI and researcher interviews, respectively, to investigate whether PAIs and researchers are reaching comparable populations, and whether differences in answers are due to the sensitive nature of the questions.
\end{abstract}

Methods: Structured interviews were conducted with 368 patients from nine OST clinics in three Swedish cities. 237 interviews were carried out by researchers, and 131 by nine PAIs (OST patients). Data were analyzed with $\chi^{2}$ test, Fisher's exact test, $t$-test, and logistic regression analysis.

Results: PAIs and researchers recruited comparable populations, with few differences in terms of individual, treatment, and social factors. However, self-reported behaviors revealed several significant differences. Alcohol consumption and drinking to intoxication was more commonly reported among patients interviewed through PAI $(\mathrm{p}<0.001$ and $\mathrm{p}=0.001$, respectively). Furthermore, the PAI group reported selling medication ( $\mathrm{p}<0.001$ last month, $\mathrm{p}<0.001$ during treatment episode), and snorting buprenorphine ( $\mathrm{p}=0.010$ last month, $\mathrm{p}=0.001$ during treatment episode) more frequently.

Conclusions: PAI is a useful method in studies of illicit drug use and a valuable complement to more traditional interviewing methods. Specifically as regards revelations of a sensitive or controversial nature, PAI seems to produce different results than researcher interviews, and possibly also more truthful responses. PAI may have considerable potential as a datagathering method also when studying other, more easily accessible populations.

Keywords: privileged access interviewing; hidden populations; drug use; self-report method; opioid substitution treatment. 


\section{Introduction}

Privileged Access Interviewing (PAI) is a method to reach populations which are difficult to gain access to by other means. PAI has primarily been used in studies about illicit drug use (Griffiths et al. 1993, Gossop 1995, Griffiths et al. 1997, Kuebler and Hausser 1997, Albery et al. 2000, Rhodes et al. 2005). In this approach the researchers rely on insiders, privileged access interviewers (PAIs) — often people who are, or have been drug users themselves — to conduct interviews with individuals in their networks.

PAI is typically based on gathering self-reported data through interviews following structured questionnaires. How such data compare to other self-reported data has seldom been discussed. Some analysts have concluded that PAI may lead to an increase in validity due to a decreased social distance between interviewer and respondent (Kuebler and Hausser 1997, Power 1994), although the issue has only been investigated in one study so far (Davies and Baker 1987). However, that study comprised of only one researcher and one PAI. We will return to it later.

In connection with a prevalence study on diversion of methadone and buprenorphine_-patients selling or sharing part or all of their medication—from opioid substitution treatment (OST) to the illicit drugs market we collected data in two different ways, through PAI, and by on-site interviews conducted by researchers. Previous studies on diversion have exclusively been based on interviews by researchers (Spunt et al. 1986, Winstock et al. 2008, Winstock and Lea 2010, Dale-Perera et al. 2012, Duffy and Baldwin 2012), and have indicated that it is uncommon for OST patients to sell or share their medication-despite research showing that these substances are common among people who inject drugs (PWID) outside treatment (Obadia et al. 2001, Lauzon et al. 2002, Varescon et al. 2002, Humeniuk et al. 2003, Davis and Johnson 2007, Håkansson et al. 2007, Vlahov et al. 2007, Yokell et al. 2011, Schmidt et al. 2013). We assumed that this paradox could be the result of under-reporting of some forms of self-reported data. In all likelihood, to disclose the use of methadone or buprenorphine to a researcher is not particularly sensitive for PWID, 
whereas it may be another matter altogether for an OST patient to admit to having diverted his/her medication.

Our hypothesis, thus, was that the PAI team would receive more truthful answers to the sensitive questions, with a higher self-reported diversion as a result. This hypothesis was borne out by our results - the percentage of patients who declared that they had sold, shared or traded their medication in the last month was more than double in interviews conducted by the PAI team (37.4\%) compared to those performed by researchers (17.2\%) (Johnson and Richert 2015a).

In this article, we carry out an in-depth comparison of the results from the two data gathering methods. First, we analyze differences between the groups in terms of individual, social, and treatment factors, in order to assess whether PAIs and researchers recruited comparable respondent populations. Then we study the answers to questions of varying degrees of sensitivity. We focus on three areas: health, current drug use, and non-adherence in treatment (diversion and other undesirable behaviors).

\subsection{The Self-reporting Method in Research on Illicit Drugs}

Self-reporting is a crucial method to measure and investigate criminality, illicit drug use, and other norm violations. Since the method was introduced in the 1950s, it has been further developed and improved, not least in terms of question design, selection criteria and datagathering methods. Nowadays, self-reported data are considered 'acceptably valid and reliable for most research purposes’ (Thornberry and Krohn 2000).

According to Farrington (2001), the really crucial aspect of using self-reported data is the empirical validity; whether the data gathered give an accurate estimate of the phenomenon under study. The empirical validity is normally measured through studies of criterion (or concurrent) validity, where self-reported information is compared with some other measure. Examples of such comparisons are statistics of arrest records or convictions in relation to crime, or drug tests in relation to drug use. 
Incorrect self-reporting may have several causes, although three factors are typically highlighted: memory issues, misunderstandings, and unwillingness to provide accurate information (Darke 1998, Thornberry and Krohn 2000). The reason for the latter may be that the respondent is apprehensive of negative consequences in the case of truthful reporting, but may also be associated with feelings of guilt and shame over having engaged in socially stigmatized behaviors (Darke 1998). 'Essentially, a self-report is a judgment call in which there is some type of decision to trust or not to trust someone, in some way,' writes Williams and Nowatzki (2005). For this reason, it is normally a precondition for correct reporting that the respondents trust the confidentiality of the study (Thornberry and Krohn 2000). Incorrect reporting may also be induced by social desirability response bias, when interviewees adapt their answers in accordance with what they think the interviewer expects or wants to hear (Darke 1998, Krumpal 2013), or in order to conform to societal norms. This phenomenon has been highlighted in sexuality research, where computer-based interviewing methods have often led to higher reporting frequencies of sensitive sexual behaviors than face-to-face interviewing (Schroder et al. 2003).

As regards drug users, studies of criterion validity have mainly focused on comparisons between self-reported drug use and data from drug tests. In a review, Darke (1998) contended that such comparisons indicate consistently high concordance. There are discrepancies, however, which may take the form of under- as well as over-reporting. Criterion validity is often high when it comes to common drugs such as tobacco, alcohol, and cannabis, while under-reporting is more frequent for harder drugs where the social acceptance is lower (Darke 1998, Thornberry and Krohn 2000, Williams and Nowatzki 2005).

PWID often give 'reasonably reliable answers to questions about drug use,' claims Darke (1998). This is often true even after a long period of time has elapsed. Furthermore, there are no apparent differences in validity between PWID and patients in treatment (Darke 1998). However, there are signs that under-reporting may be common among less experienced drug users, in particular among adolescents (Williams and Nowatzki 2005, Magura 2010). 
Over-reporting of drug use has also been documented in several studies. Overreporting may be due to individuals exaggerating their drug use in connection with assessments, in order to increase their chances of receiving help (Darke 1998, Williams and Nowatzki 2005). Apparent over-reporting may also increase when self-reported drug use cannot be confirmed through urine- or blood-based drug tests. The time frame for detecting many of these substances is limited. This means that some cases of correctly reported drug use remain undetected in the drug tests. In such cases, however, the validity issues lie with the drug tests rather than the self-reports.

\subsection{Privileged Access Interviewing — a Useful Method on Sensitive Topics?}

Illicit drug use and sale of illicit drugs are to a great extent clandestine activities, and as such often inaccessible to researchers. 'As with any deviant or illegal activity, its participants are often wary of outsiders, particularly those who are inquisitive,' concludes Power (1994). The point of PAI is to enlist people with greater access to illicit drug users than researchers haveeither through frequent contacts with drug users, or because they themselves belong, or have belonged, to this community (Griffiths et al. 1993, Kuebler and Hausser 1997).

Hughes (1977) used methadone patients as interviewers when he investigated the prevalence of heroin use in Chicago in the 1970s, but it was not until the spread of HIV/AIDS among PWID had turned into an important area of research in the 1980s that PAI began to be developed and used more extensively. Sometimes another term, 'indigenous fieldworkers,' is used (Wiebel 1988, Power \& Harkison 1993, Power 1994, Power 1995). This concept has been defined as 'staff who are current or former high-status members of the communities targeted for intervention' (Wiebel 1988).

PAIs may be employed to perform various functions: as outreach workers, community guides, observers, or peer-educators (Power 1994). However, their most frequent function is as interviewers. With the aid of structured questionnaires, PAIs are able to collect great quantities of data over a limited period of time, from substantial numbers of drug users 
from various networks (Griffiths et al. 1993). PAI is less costly than alternative methods, such as respondent-driven sampling (Platt et al. 2006).

The validity of the PAI method has only been explored to a limited extent. An important issue is the quality of the work performed by the interviewers (Kuebler and Hausser 1997). The most immediate and fundamental issue in this context is to ensure that the interview really has taken place. Researchers have used various types of controls for this purpose, such as intra-questionnaire safeguards, observing PAIs while interviewing, and to ask to meet some respondents (Griffiths et al. 1993, Power 1994, Kuebler and Hausser 1997). Another option is to let each respondent fill out one page of the interview form, in order to verify that their handwriting differs (Kuebler and Hausser 1997).

Nevertheless, the risk of deception should not be exaggerated-PAIs exposed as having fabricated interviews is rare. The PAI method is furthermore based on a mutual trust between researchers and interviewers, and this trust would be damaged by any too palpable displays of distrust. Consequently, more important than control measures is to ensure that the interviewers are well-educated and trained in interview techniques, and that they are continuously supported in their task by routine debriefings and regular feedback (Griffiths et al. 1993, Power 1994, Kuebler and Hausser 1997).

Another crucial issue concerns the general applicability of the results - their external validity in other words. As with all methods based on non-probability selection, PAI may cause sampling bias (Kuebler and Hausser 1997). PAIs will, in all likelihood, primarily recruit respondents from their own milieu or network, which may cause bias in the data. In order to reduce this problem, and to increase the external validity, a team of PAIs should be recruited from various milieus and networks (Griffiths et al. 1993, Power 1994, Gossop 1995, Kuebler and Hausser 1997).

As pointed out in the introduction, some researchers have assumed that PAI may increase the empirical validity in comparison to structured interviews conducted by researchers (Power 1994, Kuebler and Hausser 1997). The basis for this claim is the research on interviewer effects which has shown that perceptions of social desirability can result in less 
truthful answers. Respondents may endeavor to make a good impression on the interviewer, and in consequence lay stress on those characteristics which they judge to be the most suitable in a given context. They may also tailor their responses to correspond to what they think the interviewer expects to hear (Webb 1981). Such effects may be intensified if the questions asked are of a sensitive nature, or seen as threatening (Power 1994), or if the social distance between interviewer and respondent is great (Johnson et al. 2000, Williams and Nowatzki 2005).

PAI helps reduce the social distance, and has the potential to defuse more sensitive questions. Having peers conduct the interviews may enhance trust in the relationship and reduce shame, guilt, or stigma associated with drug use. Theoretically speaking, the method therefore ought to lead to 'less untrue answers due to social desirability' (Kuebler and Hausser 1997).

It is conceivable, however, that PAI, rather than reducing bias, instead introduces another form of bias. In certain situations the interviewees may want to exaggerate or downplay particular behaviors when interviewed by one of their peers rather than a researcher. Prior to our study,only one study comparing PAI and research interviews has been conducted (Davies and Baker 1987). In that study, which had a test-retest design, one PAI (a locally well-known heroin user) and one 'conventional' interviewer conducted similar interviews with the same respondents; 20 heroin users who were interviewed and reinterviewed in the space of 10-14 days. The study found that the respondents presented themselves differently depending on who conducted the interview, and that they tended to describe themselves as heavier users and as more addicted to the researcher. Nevertheless, the results should be interpreted with caution, since the empirical data set was so limited. The differences measured could have been caused by the individual demeanors on the part of the two interviewers. 


\section{Methods}

\subsection{Participants and Recruitment}

In its entirety, the diversion project comprises 509 interviews with participants (411 OST patients and 98 heroin users) recruited in five cities in the South of Sweden. For this article, we only made use of the interviews with OST patients from the three cities of Gothenburg, Lund, and Malmö ( $\mathrm{n}=368)$. The drug situation and treatment policies in these cities differ to some extent from the other two locations in our study, which we therefore decided to exclude.

The interviews took place between May and December, 2012. During this period there were nine OST clinics in total in the three locations, all of which were included in the study. The inclusion criterion was that the respondents had been admitted to OST for at least four weeks.

Researcher interviews ( $\mathrm{n}=237)$ were performed on site by the project coordinators (Johnson and Richert) and three project assistants (two female and one male), who had received the same training as the PAIs. Posters were displayed at the clinics one to two weeks before our arrival. Written information and scheduling lists were left with a secretary. We then spent between two and ten working days at each clinic, carrying out scheduled interviews, and recruiting additional participants among the visiting patients. The interviews were carried out in seclusion in rooms at the clinics or in adjoining buildings. The PAI interviews ( $\mathrm{n}=131)$ took place in Gothenburg and Malmö (seven clinics), and were conducted in various locations outside the clinics (at home or in public places, such as cafes and parks). The respondents were people recruited by the PAIs from their respective networks of friends and acquaintances. All respondents were currently in OST.

\subsection{Recruitment and Training of PAIs}

We recruited a PAI team consisting of nine OST patients. In Gothenburg, we asked an acquaintance who was employed at the OST clinic for suggestions of four individuals, whom we first interviewed and then asked whether they were interested in working on the project. In 
Malmö, we recruited five people whom we had interviewed ourselves, and had made a good impression. In the recruitment process we applied the criteria formulated by Griffiths and his colleagues (1993), i.e. that the interviewers should have (1) wide networks of contacts in various patient communities, (2) individual characteristics which means that they are not running the risk of appearing threatening to the target population, (3) sufficient social and intellectual capability to be able to conduct structured interviews, and (4) a stable lifestyle making them reliable enough to be employed as interviewers. The PAI team is described in Table 1.

\section{/Table 1/}

All assisting interviewers (PAIs as well as projects assistants) went through a one-day training session (held on three different occasions) where they familiarized themselves with the structured questionnaire, and practiced the interview technique on each other. The information given to respondents, the issue of informed consent, questions of ethics, and security procedures were also thoroughly discussed during the training.

The data-gathering process was performed under close supervision by the first author. After the first regular interview, a comprehensive debriefing took place, which was then followed up every second or third interview, when the PAIs handed over the completed questionnaires. During these debriefings, very few issues were identified, although on a few occasions interviewers were asked to contact some of the respondents for further clarifications.

Each PAI received SEK 10,000 (approx. EUR 1,100) in remuneration for a total of 15 interviews. This sum was also awarded to those who conducted fewer interviews. Three PAIs carried out additional interviews, and they received SEK 700 (EUR 77) per extra interview.

On the whole, the PAI team did a very good job, and we found them all to be conscientious and committed to the project. Once the data gathering had concluded, several of the interviewers continued to follow our work with the project, and also assisted us with suggestions for interpretations of the results. 


\subsection{Interview Procedure}

The interview procedure was the same, regardless of who performed the interview. The participants received both oral and written information about the project and its aims. We explained that the study was completely confidential, that participation would not affect their individual treatment, and that they were free to end the interview at any point.

The interviews followed a standardized questionnaire which we had developed in cooperation with colleagues and representatives for the Swedish Drug Users Union. The questionnaire consisted of 106 close-ended and five open-ended question covering the following topics: demographic information, health, social situation, drug use (past and present), experiences of illicit use of OST medication, healthcare experiences, current OST status and views on the treatment form, attitudes to diversion, and finally, personal experiences of diversion. Each interview lasted 60 minutes on average. Afterwards the participants were given a gift voucher (value SEK 200, approx. EUR 22) or a book as a token of our appreciation.

\subsection{Variables and Statistical Analysis}

The variables in the categories 'Individual Factors', 'Health', 'Social Factors', and 'Current Drug Use' were based on questions from the Swedish version of the Addiction Severity Index (revised 2009). As regards treatment factors and non-adherence in treatment we devised our own questions.

For treatment factors the questions were formulated as follows: (1) Medication: 'Which medication do you receive?' (2) Dose: 'What is your current dose?' (3) Handing-out procedures: ‘How often do you collect your medication?' (Number of days/week or more infrequently). (4) Treatment duration: 'How long have you been in substitution treatment during this treatment episode?' (Number of months). (5) Previous OST: 'Have you ever been in OST prior to this treatment episode?' 
For non-adherence in treatment the questions were formulated as follows: 'During the current treatment episode [alternatively 'the last month'], have you ever (a) saved part of your dose for later use, (b) failed to collect your dose, (c) given away part of your dose, (d) sold part of your dose, (e) traded part of your dose for other substances, (f) bought extra medication for your own use, (g) injected your methadone (h) snorted your buprenorphine [buprenorphine-naloxone]?'

The data were analyzed based on interviewer category—i.e. one researcher group, and one PAI group — by means of calculations of frequencies and averages, as well as cross tabulations. Inter-population statistical differences in the data set were calculated by $\chi^{2}$-test, Fisher's exact test, and t-test. Then multivariate analyses were conducted by means of logistic regression analysis. All calculations were performed with the SPSS software, version 20 for Windows.

\subsection{Ethics}

The project was conducted in accordance with the Swedish Ethical Review Act (SFS 2004:460). The design and execution of the project was reviewed and approved by the Regional Ethical Review Board at Lund University.

\section{Results}

\subsection{PAI versus Researcher Interviews-the Samples}

In order to compare differences in answers for various types of questions, it is essential initially to try to establish whether PAIs and researchers recruited comparable samples of respondents from the total population. Table 2 presents a comparison between the PAI group and the researcher group with reference to individual, treatment, and social factors. 
/Table 2/

As regards individual factors, the similarities between the groups are conspicuous. The only obvious difference was that the PAI group contained significantly fewer respondents born abroad $\left(\chi^{2}\right.$-test, $\left.\mathrm{p}=0.002\right)$. This is probably due to the fact that only one of the nine members of the PAI team was born abroad.

In terms of treatment factors, the similarities between the groups are also farreaching. There were significant differences when it comes to treatment duration; the researcher group contained more patients who were new to the treatment (treatment duration 0-6 months), while the PAI group had slightly more respondents with a treatment duration of $1-3$ years $\left(\chi^{2}\right.$-test, $\left.\mathrm{p}=0.013\right)$. In all likelihood, this is due to the fact that the researchers recruited their respondents in the waiting rooms at the clinics. ${ }^{*}$

Also in terms of social factors most signs point to the PAI group and the researcher group being comparable. The only significant difference concerned the social networks of the respondents. A higher proportion of the PAI group reported that they mainly socialized with family or relatives with current drug problems, while a higher proportion in the researcher group claimed that they primarily associated with family or relatives without such issues $\left(\chi^{2}-\right.$ test, $\mathrm{p}=0.007)$.

\subsection{PAI versus Researcher Interviews-a Comparison of Different Types of Self-reported} Data

A comparison between the responses from the PAI group and the researcher group to questions concerning health, current drug use, and non-adherence in treatment is presented in Table 3.

\section{/Table 3/}

In terms of health, there were no significant differences between the PAI group and the researcher group. The answers to the health-related questions were strikingly similar, 
except for Hepatitis C, where the proportion claiming to be HCV positive was somewhat higher in the PAI group.

Self-reported illicit drug use in the last month was almost identical for the two groups, $48.1 \%$ versus $48.7 \%$ ( $\chi^{2}$-test, $\left.p=0.907\right)$. The trends vary for specific drugs, but none of these differences are significant.

One of the greatest differences in the data concerns alcohol consumption. Selfreported alcohol use in the last month was considerably higher in the PAI group than in the researcher group, $65.4 \%$ compared to $46.0 \%$. The difference is significant $\left(\chi^{2}\right.$-test, $\left.p<0.000\right)$, and when it comes to drinking to intoxication the difference is even more marked, 38.5\% versus $22.5 \%\left(\chi^{2}\right.$-test, $\left.\mathrm{p}=0.001\right)$.

When the data on alcohol consumption are broken down in greater detail, another pattern emerged: the differences are mainly to be found among the patients who have not reported any illicit drug use. Among them, 38.8\% have reported drinking to intoxication in the PAI group, while only $13.3 \%$ did so in the researcher group, a significant difference $\left(\chi^{2}\right.$ test, $\mathrm{p}<0.000)$. Among the respondents who have declared that they have used at least one illicit drug in the last month the difference was noticeably less-38.8\% in the PAI group compared to the $32.2 \%$ in the researcher group—and not significant $\left(\chi^{2}\right.$-test, $\left.\mathrm{p}=0.509\right)$.

When looking at non-adherence in treatment, there were several significant differences. The proportion who reported that they had sold medication during the treatment episode was nearly double in the PAI group compared to the researcher group, $47.3 \%$ and $26.6 \%$ respectively. Regarding the selling of medication in the last month, the differences were even greater-more than three times as many respondents in the PAI group admitted to doing this than in the researcher group, $26.0 \%$ compared to $8.4 \%$. Both differences are significant $\left(\chi^{2}\right.$-test, $\left.\mathrm{p}<0.001\right)$. The differences for the combination variable 'Sold, traded or shared medication' were also clearly significant, both for the whole treatment episode $\left(\chi^{2}\right.$-test, $\mathrm{p}=0.003)$ and in the last month $\left(\chi^{2}\right.$-test, $\left.\mathrm{p}<0.001\right)$. Another significant difference was found for the variable 'Traded medication during the treatment episode' $\left(\chi^{2}\right.$-test, $\left.p=0.011\right)$. The 
differences were not significant, however, with regards to 'Given away medication', although the trend was going in the same direction as for other diversion activities.

Another problematic behavior in OST is when patients take their medication in an incorrect manner, for instance snorting buprenorphine or injecting methadone. For buprenorphine patients there were significant differences, with a higher proportion of the PAI group reporting experiences of having snorted, both during the treatment episode $\left(\chi^{2}\right.$-test, $\mathrm{p}=0.001)$ and in the last month $\left(\chi^{2}\right.$-test, $\left.\mathrm{p}<0.010\right)$. On the other hand, there were no differences for injecting methadone. When it comes to undesirable behaviors of presumably less serious nature, such as saving part of one's dose or failing to collect medication at the clinic, there were no significant differences. This also goes for the behavior of buying extra methadone or buprenorphine for personal use.

\subsection{Multivariate Analyses}

In Tables 4.1 and 4.2, we present two examples of logistic regression analysis where we investigate whether differences in responses between the two types of interviewers remain even following multivariate analysis. As dependent variables we used 'current alcohol use' and 'sold dose in the last month'. As independent variables we used 'type of interviewer', 'native country', 'treatment duration', 'previously in jail', and 'current social circle'. These last four variables are the individual, treatment-related, and social factors where significant or close to significant differences were identified between respondents interviewed by PAIs and researchers, respectively.

/Table 4.1 and 4.2/

As can be seen from the tables, the differences in responses between the two interviewer types were significant also in the multivariate analysis. There is a connection between PAIs and an increased percentage of positive responses, both for 'current alcohol use' (OR=1.850, 95\% CI: 1.159-2.952) and for 'sold dose in the last month' (OR=3.441, 95\% CI: 1.839-6.439). Some of the other independent variables also exhibit covariation with the 
dependent variables_-for instance, self-reported alcohol consumption was higher for those who claimed their social circle principally consisted of active drug users. A further analysis of this connection falls outside the scope of this article, however. ${ }^{\dagger}$

\section{Discussion}

Section 3.1 indicate that the researchers and the PAI team on the whole recruited comparable groups of OST patients — or put another way, that the external validity was commensurate. Of the 19 individual, treatment, and social factors we compared, there were three displaying significant differences between the groups. Two of those differences, country of origin and treatment duration, are probably caused by the composition of the PAI team, and the fact that the researchers exclusively recruited their respondents at the clinics. The third difference concerns the self-reported social network, where the PAI group respondents - to a greater extent than respondents from the researcher group—stated that they mainly associated with friends and family with current drug problems. A likely explanation for this is that the question was seen as sensitive, and that the PAI team by virtue of this received different, and possibly more truthful answers. This interpretation is supported by the fact that the groups are comparable in all other respects, and that there are no inter-group differences in terms of illicit drug use. Alcohol use and drinking to intoxication are reported more often by the respondents in the PAI group than in the researcher group—-we return to this below-but this is independent of their stated primary social network. ${ }^{\ddagger}$

Sections 3.2 and 3.3 support our hypothesis that PAI may lead to differences in answers compared with researcher interviews, when data is gathered from OST patients. This seems particularly to be the case for issues which may be perceived as sensitive in a treatment context.

As regards self-reported health, there were no significant differences between the groups, which indicate that such issues appear relatively non-controversial for OST patients. Nor were there any differences in terms of illicit drug use. This can be connected to previous studies on criterion validity (see section 1.1) which indicate that such self-reported data often 
correspond relatively well with data from drug tests. Thus our results deviate from the study by Davies and Baker (1987), discussed in section 1.2. Davies and Baker's study had a testretest design, which is to be preferred methodologically speaking, but our study was based on a considerably larger data set, and not least important, we employed more interviewers.

In terms of alcohol consumption and drinking to intoxication, there were substantial differences between the researcher group and the PAI group. On the basis of previous validation studies, the differences are counterintuitive, since under-reporting mainly has been documented for drugs carrying a greater social stigma (such as heroin and cocaine), not for legal drugs such as alcohol and tobacco (Darke 1998).

One possible explanation is that alcohol is one of the hardest substances to detect with the regular drug tests which take place during treatment. Drugs such as benzodiazepines, cannabis, and heroin are controlled through urine tests, and can be detected for days, even weeks after they have been taken. Alcohol consumption, on the other hand, is measured with a breathalyzer, and can only be detected as long as the drug is present in the air exhaled. It is possible that some patients are used to hiding their alcohol consumption from the staff, and that they routinely do the same with us researchers.

Another, and probably more important explanation is that there is a social stigma attached to alcohol in this group of patients. It is well-known that a substantial minority of OST patients increase their alcohol consumption when entering OST. Previous studies indicate that alcohol-related problems occur among $20-50 \%$ of patients in methadone treatment (Anglin et al. 1989, Stastny and Potter 1991, El-Bassel et al. 2006, Stenbacka et al. 2007). As researchers we know that our respondents are dependent on narcotic drugs, and they know that we know — this is the very point of departure for the interview. On the other hand, we know nothing about their relationship with alcohol. Anyone wishing to appear in a slightly better light may therefore have reasons to hide their alcohol consumption. Such arguments may not be as relevant in connection with the PAI team, which, by virtue of their insider status have a different understanding, and often even prior knowledge about the drinking habits of their respondents. 
If any one group of patients is generally anxious to appear in as positive a light as possible before the researchers, this should be particularly noticeable when it comes to alcohol consumption, since this drug is decidedly more common than illicit drug use. The existence of such a 'boy scout effect' is supported by the fact that the main differences between the researcher group and the PAI group were to be found among the patients who have reported no illicit drug use.

The comparison of non-adherence in treatment, finally, also lends support to the hypothesis that PAIs could lead to different answers to sensitive questions. For some nonadherence behaviors, arguably of a less sensitive nature, no differences were found. With regards to patients who claimed to have saved part of their dose, failed to collect it, or bought medication for personal use, there were no differences between the groups. From the talks we had with some of our respondents it became clear that this type of behavior was seen as natural and unproblematic from their perspective. Anyone can be held up for one reason or another when going to collect medication, and should they ever miss a collection, or lose their medication, it is only rational to keep some doses in stock. Buying extra medication for personal use, also stood out as a behavior which needed no justification. The behavior was more common during the titration phase, but was also described as a way out if they failed to pick up their medication.

Other non-adherence behaviors are highly sensitive and controversial. Diversion has long been a contentious issue in the Swedish drugs policy debate, and has been linked with an increase in opioid-related mortality outside treatment (Johnson 2011). Patients who are caught selling their medication run a severe risk of being discharged from treatment.

A current breach of the rules ought therefore to be more sensitive than one which occurred further back in time. This was corroborated by our data. Accordingly, from a moral perspective, it ought to be a more sensitive issue to have sold medication, than to have traded or given it away (Johnson \& Richert 2014, Johnson \& Richert 2015b). This was also corroborated by our data. The trend for the arguably least controversial behavior-having given away medication at some point—-pointed in the expected direction, but was not 
significant. In contrast, the arguably most controversial behavior-having sold medication in the last month—was reported by three times as many patients in the PAI group as in the reference group. In other words, there appears to be a pattern where more sensitive and controversial issues were connected with greater differences in the responses given depending on the type of interviewer.

Based on our study, we are unable to draw any definitive conclusions as to why a higher percentage of the patients interviewed by PAIs would admit to having consumed alcohol or engaged in specific non-adherence behaviors. It is conceivable that the reason is a shorter social distance between the interviewer and the respondent, a hypothesis propounded by previous research (Kuebler and Hausser 1997, Johnson et al. 2000, Williams and Nowatzki 2005). Another possibility is that the respondents did not try to hide certain sensitive behaviors from the PAIs since they, by virtue of their acquaintanceship, already knew that the PAIs had prior knowledge of them. However, the differences could also at least partly be explained by social desirability response bias. In subcultures of drug users 'a moral economy of sharing' often develops, a norm system where it is considered unethical not to share the substances used with friends and acquaintances in withdrawal. The existence of such a norm system, which both the respondents and the PAIs form part of, could potentially contribute to higher reporting frequencies of diversion.

One limitation of this study is that the individual PAIs and research assistants have conducted only a limited number of interviews each (range: 8 to 22). Differences in terms of experience and approaches, as well as - for the PAIs—status and standing within the patient collective, may also have had an influence on the answers they received. Consequently, it is not particularly informative or instructive to report statistics on answers given to individual interviewers (and potentially problematic from any ethical point of view). It should be pointed out, however, that the divergences between the two types of interviewers remain consistent, also at the individual level. For instance, eight out of nine PAIs reported higher levels of alcohol consumption for their respondents compared to the average for the patient population as a whole, whereas three out of five researchers noted lower levels. As regards current 
diversion (the variable 'Sold, traded or given away previous month'), eight out of nine PAIs recorded higher levels compared to the population average, while four out of five researchers recorded lower levels.

Another limitation which must be mentioned is the interview locations. The researchers conducted all interviews at the treatment sites, whereas the PAI interviews were conducted elsewhere. Being interviewed at the location where one is also receiving treatment may elicit greater resistance to acknowledging certain behaviors which interfere with treatment or suggest non-adherence, even though the interviews were conducted behind closed doors. Unfortunately, we were unable to account for this aspect in the study design. The different locations constitute a significant limitation which does prevent us from drawing any definitive conclusions as to whether the observed differences are due to 'interviewer effects’ alone.

In conclusion, our study shows that PAI is a useful method in studies of illicit drug use and pertinent issues, and a valuable complement to more traditional interviewing methods. In particular, in terms of information of a sensitive or controversial nature, PAI seems to elicit different answers than researcher interviews, and possibly even an increase in more 'truthful' responses. What is considered sensitive and controversial may, of course, vary — what is sensitive for the OST patients in our study will not necessarily be so for, say, injecting drug users outside treatment or young people with a more experimental drug use. What is perceived as sensitive could also be dependent on the interviewer-PAIs could potentially introduce a different bias rather than reduce bias as a whole.

Also, our study indicate that PAI may have considerable potential as a data-gathering method when it comes to other populations, not only those which are hard to reach. OST patients are one such well-defined population, as are other groups of drug users who stand in regular contact with society’s healthcare and support systems. If used judiciously, the PAI method could also bring other benefits. It could lead to an increased user influence in research, open up the possibility of researchers discussing their results and their implications 
with people who occupy an insider position, as well as contribute to the empowerment of those who are recruited as PAIs.

More research is needed in order to paint a clearer picture of the strengths and weaknesses of the PAI method. Research comparing different interviewing methods with each other, as well against some form of 'golden standard' for validation purposes (such as biomarkers for alcohol), would be of particular interest.

\section{References}

Albery I.P., Strang J., Gossop M. \& Griffiths P. (2000) Illicit drugs and driving: Prevalence, beliefs and accident involvement among a cohort of current out-of-treatment drug users. Drug and Alcohol Dependence 58(1-2): 197-204.

Anglin M.D., Almog I.J., Fisher D.G. \& Peters K.R. (1989) Alcohol use by heroin addicts: Evidence for an inverse relationship. A study of methadone maintenance and drug-free treatment samples. The American Journal of Drug and Alcohol Abuse 15(2): 191-207.

Dale-Perera A., Goulão J. \& Stöver H. (2012) Quality of care provided to patients receiving opioid maintenance treatment in Europe. Heroin Addiction and Related Clinical Problems 14(4): 23-38.

Darke S. (1998) Self-report among injecting drug users: A review. Drug and Alcohol Dependence 51(3): 253-63.

Davies J.B. \& Baker R. (1987) The impact of self-presentation and interviewer bias effects on self-reported heroin use. British Journal of Addiction 82(8): 907-12.

Davis W.R. \& Johnson B.D. (2007) Prescription opioid use, misuse, and diversion among street drug users in New York City. Drug and Alcohol Dependence 92(1-3): 267-76.

Duffy P. \& Baldwin H. (2012) The nature of methadone diversion in England: A Merseyside case study. Harm Reduction Journal 9: 3.

El-Bassel N., Schilling R.F., Turnbull J.E. \& Su K-H. (2006) Correlates of alcohol use among methadone patients. Alcoholism: Clinical and Experimental Research 17(3): 681-6.

Farrington D.P. (2001) What has been learned from self-reports about criminal careers and the causes of offending? Report to Home Office. Cambridge: Institute of Criminology.

Gossop M. (1995) Chasing the dragon: Research into heroin smoking in Britain. European Addiction Research 1(1-2): 42-9.

Griffiths P., Gossop M., Povis B. \& Strang J. (1993) Reaching hidden populations of drug users by privileged access interviewers: Methodological and practical issues. Addiction 88(12): 1617-26. 
Griffiths P., Gossop M., Wickenden S., Dunworth J., Harris K. \& Lloyd C. (1997) A transcultural pattern of drug use: Qat (khat) in the UK. The British Journal of Psychiatry 170: 281-4

Hughes P. (1977) Behind the Wall of Respect: Community Experiments in Heroin Addiction Control. Chicago, Ill.: University of Chicago Press.

Humeniuk R., Ali R., McGregor C. \& Darke S. (2003) Prevalence and correlates of intravenous methadone syrup administration in Adelaide, Australia. Addiction 98(4): 413-18.

Håkansson A, Medvedeo A, Andersson M \& Berglund M (2007) Buprenorphine misuse among heroin and amphetamine users in Malmö, Sweden: Purpose of misuse and route of administration. European Addiction Research 13(4): 207-15.

Johnson B. (2011) Metadon och buprenorfin - attraktiva på gatan och utanför vården. Läkartidningen 108(45):2309-11.

Johnson B. \& Richert T. (2014) Diversion of methadone and buprenorphine from opioid substitution treatment-A staff perspective. Journal of Psychoactive Drugs 46(5):427-35.

Johnson B. \& Richert T. (2015a) Diversion of methadone and buprenorphine by patients in opioid substitution treatment in Sweden: Prevalence estimates and risk factors. International Journal of Drug Policy 26(2): 183-90.

Johnson B. \& Richert T. (2015b) Diversion of methadone and buprenorphine from opioid substitution treatment: The importance of patients' attitudes and norms. Journal of Substance Abuse Treatment http://dx.doi.org/10.1016/j.jsat.2015.01.013

Johnson T.P., Fendrich M., Shaligram C., Garcy A. \& Gillespie S. (2000) An evaluation of the effects of interviewer characteristics in an RDD telephone survey of drug use. Journal of Drug Issues 30(1): 77-102.

Krumpal, I. (2013). Determinants of social desirability bias in sensitive surveys: A literature review. Quality \& Quantity 47(4): 2025-47.

Kuebler D. \& Hausser D. (1997) The Swiss hidden population study: Practical and methodological aspects of data collection by privileged access interviewers. Addiction 92(3): 325-34.

Lauzon P., Vincelette J., Bruneau J., Lamothe F., Lachance N., Brabant M. \& Soto J. (2002) Illicit use of methadone among IV drug users in Montreal. Journal of Substance Abuse Treatment 11(5): 457-61.

Magura S. (2010) Validating self-reports of illegal drug use to evaluate national drug control policy: A reanalysis. Evaluation and Program Planning 33(3): 234-7.

Obadia Y., Perrin V., Feroini I., Vlahov D. \& Moatti J.P. (2001) Injecting misuse of buprenorphine among French drug users. Addiction 96(2): 267-72.

Platt L., Wall M., Rhodes T., Judd A., Hickman M., Johnson L.G., Renton A., Bobrova N. \& Sarang A. (2006) Methods to recruit hard-to-reach groups: Comparing two chain referral 
sampling methods of recruiting injecting drug users across nine studies in Russia and Estonia. Journal of urban Health 83(7): i39-53

Power R. (1994) Some methodological and practical implications of employing drug users as indigenous fieldworkers. In Boulton M. (ed.) Challenge and Innovation. Methodological Advances in Social Research on HIV/AIDS. London: Taylor Francis.

Power R. (1995) A model for qualitative action research amongst illicit drug users. Addiction Research 3(3): 165-81.

Power R. \& Harkison S. (1993) Accessing hidden populations: The use of indigenous interviewers. In Aggleton P., Davies P. \& Hart G. (eds.) AIDS: Facing the Second Decade. London: The Falmer Press.

Rhodes T., Platt L., Maximova S., Koshkina E., Latishevskaya N., Hickman M., Renton A., Bobrova N., McDonald T. \& Parry J.V. (2005) Prevalence of HIV, hepatitis C and syphilisamong injecting drug users in Russia: A multi-city study. Addiction 101(2): 252-66.

Schmidt C.S., Schulte B., Wickert C., Thane K., Kuhn S., Verthein U. \& Reimer J. (2013) Non-prescribed use of substitution medication among German drug users: Prevalence, motives and availability. International Journal of Drug Policy 24(6): e111-14.

Schroder K.E., Carey M.P. \& Vanable P.A. (2003) Methodological challenges in research on sexual risk behavior: II. Accuracy of self-reports. Annals of Behavioral Medicine 26(2): 104 123.

Spunt B., Hunt D.E., Lipton D.S. \& Goldsmith D.S. (1986) Methadone diversion: A new look. The Journal of Drug Issues 16(4): 569-83.

Stastny D. \& Potter M. (1991) Alcohol abuse by patients undergoing methadone treatment programmes. British Journal of Addiction 86(3): 307-10.

Stenbacka M, Beck O., Leifman A., Romelsjö A. \& Helander A. (2007) Problem drinking in relation to treatment outcome among opiate addicts in methadone maintenance treatment. Drug and Alcohol Review 26(1): 55-63.

Thornberry T.P. \& Krohn M.D. (2000) The self-report method for measuring delinquency and crime. In Duffee D. (ed.) Measurement and Analysis of Crime and Justice. Washington, DC: The National Institute of Justice.

Varescon I., Vidal-Trecan G., Nabet N. \& Boissonnas A. (2002) Buprenorphine abuse: High dose intravenous administration of buprenorphine. Encephale 28(5): 397-402.

Vlahov D., O’Driscoll P., Mehta S.H., Ompad D.C., Gern R., Galai N. \& Kirk G.D. (2007) Risk factors for methadone outside treatment programs: Implications for HIV treatment among injection drug users. Addiction 102(5): 771-7.

Webb E.J., (1981) Nonreactive measures in the social sciences. Boston, Mass.: Houghton Mifflin.

Wiebel W.W. (1988) Combining ethnographic and epidemiologic methods for targeted AIDS interventions: The Chicago model. In: Battjes R.J. \& Pickens R.W. (eds.) Needle-Sharing 
Among Intravenous Drug Abusers: National and International Perspective. NIDA Research Monograph 80.

Winstock A.R. \& Lea T. (2010) Diversion and injection of methadone and buprenorphine among clients in public opioid treatment clinics in New South Wales, Australia. Substance Use \& Misuse 45(1-2): 240-52.

Winstock A.R., Lea T. \& Sheridan J. (2008) Prevalence of diversion and injection of methadone and buprenorphine among clients receiving opioid treatment at community pharmacies in New South Wales, Australia. International Journal of Drug Policy 19(6): 450 8.

Williams R.J. \& Nowatzki N. (2005) Validity of Adolescent Self-Report of Substance Use. Substance Use \& Misuse 40(3): 299-311.

Yokell M.A., Zaller N.D., Green T.C. \& Rich J.D. (2011) Buprenorphine and buprenorphine/naloxone diversion, misuse, and illicit use: An international review. Current Drug Abuse Reviews 4(1): 28-41. 
Table 1. The privileged access interviewing team.

\begin{tabular}{||l|c|c|c|c|c|c||}
\hline \hline City & Gender & Age & $\begin{array}{c}\text { Years of } \\
\text { heroin use }\end{array}$ & $\begin{array}{c}\text { Years in } \\
\text { OST }\end{array}$ & Employed & $\begin{array}{c}\text { No. of inter- } \\
\text { views made }\end{array}$ \\
\hline Gothenburg & $\mathrm{F}$ & 37 & 5 & 1 & No & 12 \\
\hline Gothenburg & $\mathrm{M}$ & 38 & 12 & 3 & No & 16 \\
\hline Gothenburg & $\mathrm{M}$ & 39 & 10 & 1 & No & 8 \\
\hline Gothenburg & $\mathrm{M}$ & 44 & 13 & 8 & No & 15 \\
\hline Malmö & $\mathrm{F}$ & 26 & 7 & 3 & No & 22 \\
\hline Malmö & $\mathrm{F}$ & 37 & $1(5)^{*}$ & 2 & Yes & 21 \\
\hline Malmö & $\mathrm{F}$ & 42 & 6 & 7 & Yes & 14 \\
\hline Malmö & $\mathrm{F}$ & 50 & 5 & 11 & Yes & 10 \\
\hline Malmö & $\mathrm{M}$ & 44 & 20 & 2 & No & 13 \\
\hline & & Mean: 39.7 & Mean: 9.2 & Mean: 4.2 & & Total: 131 \\
\hline
\end{tabular}

* One year of heroin use, preceded by five years of ketobemidone use. 
Table 2. A comparison of recruitment of respondents by PAls and researchers.

\begin{tabular}{|c|c|c|c|c|}
\hline Variables & $\begin{array}{c}\mathrm{N} \\
(368)\end{array}$ & $\begin{array}{l}\text { Researcher } \\
\text { group (237) }\end{array}$ & PAI group (131) & $\begin{array}{l}\text { P-value } \\
(95 \% \mathrm{Cl})\end{array}$ \\
\hline \multicolumn{5}{|l|}{ INDIVIDUAL FACTORS } \\
\hline Gender (male) & 368 & $74.7(237)$ & $72.5(131)$ & 0.651 \\
\hline Age (mean) & 368 & $39.43(237)$ & $39.51(131)$ & 0.933 (a) \\
\hline Civil status (married/live-in partner) & 368 & $31.2 \%(74)$ & $29.8 \%(39)$ & 0.772 \\
\hline Native country (Sweden) & 368 & $75.1 \%(178)$ & $88.5 \%(116)$ & $0.002 t$ \\
\hline Education (> grade school) & 368 & $54.0 \%(128)$ & $53.4 \%(70)$ & 0.916 \\
\hline Accommodation (own home/first-hand let) & 368 & $58.6 \%(139)$ & $57.3 \%(75)$ & 0.795 \\
\hline Regular heroin use, years (mean) & 359 & $9.90(230)$ & 10.79 (129) & $0.230(a)$ \\
\hline Overdosed on heroin prior to treatment & 368 & $66.7 \%(158)$ & $61.8 \%(131)$ & 0.352 \\
\hline \multicolumn{5}{|l|}{ TREATMENT FACTORS } \\
\hline Medication & 368 & & & \\
\hline Methadone & 208 & $53.5 \%(131)$ & $58.8 \%(77)$ & 0.326 \\
\hline Mono-buprenorphine & 104 & $27.4 \%(65)$ & $29.8 \%(39)$ & \\
\hline Buprenorphine-naloxone & 56 & $17.3 \%(41)$ & $11.5 \%(15)$ & \\
\hline Dispensing procedures & 368 & & & \\
\hline 5-7 days/week & 124 & $33.3 \%(79)$ & $34.4 \%(45)$ & 0.705 \\
\hline 2-4 days/week & 139 & $36.7 \%(87)$ & $39.7 \%(52)$ & \\
\hline More infrequently & 105 & $30.0 \%(71)$ & $26.0 \%(34)$ & \\
\hline Treatment episode (duration) & 366 & & & \\
\hline $0-6$ months & 90 & $29.2 \%(69)$ & $16.2 \%(21)$ & $0.013^{*}$ \\
\hline 7-12 months & 56 & $16.1 \%(38)$ & $13.8 \%(18)$ & \\
\hline $1-3$ years & 123 & $28.8 \%(68)$ & $42.3 \%(55)$ & \\
\hline$>3$ years & 97 & $25.8 \%(61)$ & $27.7 \%(36)$ & \\
\hline Previous OST & 368 & $37.6 \%(89)$ & $34.4 \%(45)$ & 0.541 \\
\hline \multicolumn{5}{|l|}{ SOCIAL FACTORS } \\
\hline Income from work & 368 & $18.6 \%(44)$ & $22.1 \%(29)$ & 0.411 \\
\hline Livelihood mainly from illegal activities & 368 & $7.6 \%(18)$ & $5.3 \%(7)$ & 0.411 \\
\hline Social network & 368 & & & \\
\hline Alone & 85 & $23.6 \%(56)$ & $22.1 \%(29)$ & $0.007+$ \\
\hline Family/relatives w/o drug problems & 211 & $61.6 \%(146)$ & $49.6 \%(65)$ & \\
\hline Family/relatives w. drug problems & 72 & $14.8 \%(35)$ & $28.2 \%(37)$ & \\
\hline No. of close friends (mean) & 366 & $2.44(235)$ & $2.44(131)$ & 0.989 (a) \\
\hline Previously homeless & 368 & $76.4 \%(210)$ & $71.8 \%(94)$ & 0.329 \\
\hline Previously in jail & 368 & $58.2 \%(138)$ & $67.9 \%(89)$ & 0.067 \\
\hline Previously sold drugs & 366 & $86.0 \%(230)$ & $87.7 \%(114)$ & 0.652 \\
\hline
\end{tabular}

* $P<0.05, \mathrm{P}<0.01$. All $\mathrm{p}$-values are derived from the $\chi^{2}$ test, except for $(\mathrm{a})$, which are derived from the $t$-test. 
Table 3. A comparison of self-reported data from PAI and researcher interviews.

\begin{tabular}{|c|c|c|c|c|}
\hline Variables & $\underset{(368)}{N}$ & $\begin{array}{l}\text { Researcher } \\
\text { group } \\
(237)\end{array}$ & PAl group (131) & $\begin{array}{l}\text { P-value } \\
(95 \% \mathrm{Cl})\end{array}$ \\
\hline HEALTH & & & & \\
\hline $\begin{array}{l}\text { Perceived health, } 1 \mathrm{v} \text {. good }-5 \mathrm{v} \text {. poor } \\
\text { Anxiety/angst issues, } 0 \text { none }-2 \text { severe } \\
\text { Sleeping difficulties, } 0 \text { none }-2 \text { severe } \\
\text { HCV positive }\end{array}$ & $\begin{array}{l}368 \\
368 \\
368 \\
368 \\
\end{array}$ & $\begin{array}{l}2.48(237) \\
0.98(237) \\
1.03(237) \\
52.7 \%(125)\end{array}$ & $\begin{array}{l}2.62(131) \\
1.05(131) \\
1.05(131) \\
64.9 \%(85)\end{array}$ & $\begin{array}{l}0.181(\mathrm{a}) \\
0.441(\mathrm{a}) \\
0.854(\mathrm{a}) \\
0.068\end{array}$ \\
\hline CURRENT DRUG USE & & & & \\
\hline $\begin{array}{l}\text { Alcohol } \\
\text { Alcohol, intoxication } \\
\text { Any illicit drug } \\
\text { Heroin } \\
\text { Benzodiazepines/tranquilizers } \\
\text { Amphetamine } \\
\text { Cocaine } \\
\text { Cannabis } \\
\text { Novel psychoactive substances }\end{array}$ & $\begin{array}{l}367 \\
366 \\
367 \\
366 \\
362 \\
353 \\
338 \\
358 \\
221 \\
\end{array}$ & $\begin{array}{l}46.0 \%(109) \\
22.5 \%(53) \\
48.7 \%(115) \\
16.2 \%(38) \\
35.6 \%(83) \\
8.4 \%(19) \\
5.5 \%(12) \\
17.5 \%(40) \\
25.8 \%(32) \\
\end{array}$ & $\begin{array}{l}65.4 \%(85) \\
38.5 \%(50) \\
48.1 \%(63) \\
13.7 \%(18) \\
31.8 \%(41) \\
14.3 \%(18) \\
7.4 \%(9) \\
17.7 \%(23) \\
37.1 \%(36) \\
\end{array}$ & $\begin{array}{l}0.000 \neq \\
0.001 \neq \\
0.907 \\
0.536 \\
0.461 \\
0.082 \\
0.486 \\
0.972 \\
0.071 \\
\end{array}$ \\
\hline NON-ADHERENCE IN TREATMENT & & & & \\
\hline $\begin{array}{l}\text { During treatment episode } \\
\text { Saved dose } \\
\text { Failed to collect dose } \\
\text { Given away dose } \\
\text { Sold dose } \\
\text { Traded dose } \\
\text { Bought extra for personal use } \\
\text { Sold, traded or given away } \\
\text { Injected methadone } \\
\text { Snorted buprenorphine }\end{array}$ & $\begin{array}{l}368 \\
368 \\
368 \\
368 \\
367 \\
366 \\
368 \\
208 \\
368 \\
\end{array}$ & $\begin{array}{l}45.6 \%(108) \\
40.9 \%(97) \\
47.7 \%(113) \\
26.6 \%(63) \\
11.4 \%(27) \\
36.2 \%(85) \\
52.7 \%(125) \\
26.0 \%(34) \\
16.5 \%(39)\end{array}$ & $\begin{array}{l}45.8 \%(60) \\
39.7 \%(52) \\
52.7 \%(69) \\
47.3 \%(62) \\
21.4 \%(28) \\
38.2 \%(50) \\
68.7 \%(90) \\
31.2 \%(24) \\
32.1 \%(42)\end{array}$ & $\begin{array}{l}0.966 \\
0.817 \\
0.359 \\
0.000 \neq \\
0.011^{*} \\
0.704 \\
0.003 \neq \\
0.418 \\
0.001 t \\
\end{array}$ \\
\hline $\begin{array}{l}\text { Last month } \\
\text { Saved dose } \\
\text { Failed to collect dose } \\
\text { Given away dose } \\
\text { Sold dose } \\
\text { Traded dose } \\
\text { Bought extra for personal use } \\
\text { Sold, traded or given away } \\
\text { Injected methadone } \\
\text { Snorted buprenorphine } \\
\end{array}$ & $\begin{array}{l}368 \\
368 \\
368 \\
368 \\
368 \\
366 \\
368 \\
208 \\
368 \\
\end{array}$ & $\begin{array}{l}20.3 \%(48) \\
14.3 \%(34) \\
13.9 \%(33) \\
8.4 \%(20) \\
3.8 \%(9) \\
10.6 \%(25) \\
17.7 \%(42) \\
4.6 \%(6) \\
3.4 \%(8) \\
\end{array}$ & $\begin{array}{l}22.1 \%(29) \\
15.3 \%(20) \\
19.1 \%(25) \\
26.0 \%(34) \\
3.8 \%(5) \\
6.1 \%(8) \\
37.7 \%(49) \\
3.9 \%(3) \\
9.9 \%(13) \\
\end{array}$ & $\begin{array}{l}0.670 \\
0.811 \\
0.193 \\
0.000 \neq \\
0.598(b) \\
0.147 \\
0.000 \neq \\
0.558(b) \\
0.010 * \\
\end{array}$ \\
\hline
\end{tabular}

* $P<0.05,+P<0.01, \neq P<0.001$. All $p$-values are taken from the $\chi^{2}$ test, except for (a) which come from the $t$-test, and (b) from the Fisher's exact test. 
Table 4.1. Logistic regression: Current alcohol consumption, interviewer category, and other control variables.

\begin{tabular}{llll}
\hline Variables in the equation & OR & $95 \% \mathrm{Cl}$ & Sign. \\
\hline Interviewer category (PAI) & 1.850 & $1.159-2.952$ & $0.010^{*}$ \\
Native country (Swedish) & 0.356 & $0.201-0.632$ & $0.000 \neq$ \\
Treatment duration (month) & 1.004 & $0.998-1.009$ & 0.216 \\
Primary social network (current drug users) & 2.592 & $1.417-4.741$ & $0.002 \dagger$ \\
Previously in jail (yes) & 1.137 & $0.724-1.788$ & 0.577 \\
\hline
\end{tabular}

* $P<0.05,+P<0.01, \neq P<0.001$. Nagelkerke $R$ square $=0.141 .365$ cases included in the analysis.

Table 4.2. Logistic regression: Sold dose last month, interviewer category, and other control variables.

\begin{tabular}{llll}
\hline Variables in the equation & OR & $95 \% \mathrm{Cl}$ & Sign. \\
\hline Interviewer category (PAI) & 3.441 & $1.839-6.439$ & $0.000 \neq$ \\
Native country (Swedish) & 0.255 & $0.075-0.862$ & $0.028^{*}$ \\
Treatment duration (month) & 1.000 & $0.991-1.008$ & 0.919 \\
Primary social network (current drug users) & 1.525 & $0.764-3.044$ & 0.232 \\
Previously in jail (yes) & 0.585 & $0.315-1.089$ & 0.091 \\
\hline
\end{tabular}

$* P<0.05, \neq P<0.001$. Nagelkerke $R$ square $=0.145 .366$ cases included in the analysis. 
${ }^{*}$ According to Swedish regulations, all new patients are required to take their medication under supervision every day for the first six months of treatment, which most likely is a contributing factor to the slight overrepresentation of new patients in the researcher group.

${ }^{\dagger}$ Logistical regression analysis was also performed for the other variables where significant bivariate connections were established for the 'interviewer type' variable (see Table 3). The connections remained significant in all analyses performed.

‡ We have studied this in a multivariate analysis (binary logistical regression, $\mathrm{n}=366$ ) with a dichotomized variable for the social network (primarily associating with individuals with current drug problems, $\mathrm{n}=71 \mathrm{vs}$. primarily associating with individuals without current drug problems/single, $\mathrm{n}=295$ ) as the dependent variable. As independent variables we used three dichotomous variables: interviewers (researchers vs. PAIs), current illicit drug use ('Yes/No', 'Last month', index with six drugs), and current alcohol use ('Yes/No', 'Last month').

Step 1 (method: Enter)

Interviewer (PAI):

OR 2.199, 95\% CI: $1.300-3.721(\mathrm{p}=0.003)$

Step 2 (method: Enter)

Interviewer (PAI):

Current illicit drug use:

OR 1.995, 95\% CI: $1.151-3.456(\mathrm{p}=0.014)$

Current alcohol use:

OR 2.454 , 95\% CI: $1.395-4.316(\mathrm{p}=0.002)$

OR 2.364, 95\% CI: $1.308-4.271(\mathrm{p}=0.004)$

The multivariate analysis indicates that the interviewer effect is distinct, and independent of illicit drug use and alcohol consumption. 